\title{
Cardiomiopatias. Uma Visão Crítica do Conceito da Classificação
}

\author{
Charles Mady, Fábio Fernandes \\ São Paulo, SP
}

A conceituação e classificação das cardiomiopatias permanecem, ainda hoje, difíceis e controversas. Atualmente, as cardiomiopatias são classificadas pela fisiopatologia dominante e, se possível, por atores etiológicos e patogênicos ${ }^{1}$. Várias modificações têm sido realizadas com o passar do tempo, mas a maioria delas com falhas e pontos criticáveis. Recentemente, mesmo com a tentativa de uniformização, realizada pela World Organization (WHO)/International Society and Federation of Cardiology (FSFC), ainda, existem dúvidas e pontos criticáveis levantados por clínicos.

A primeira descrição de cardiomiopatia foi realizada em 1891 por Krehl. O termo cardiomiopatia foi introduzido na literatura médica por Brigden em 1957, no seu artigo "Uncommon myocardial diseases. The non-coronary cardiomyopathies", publicado na revista Lancet, onde é discutida a dificuldade de classificação e a diversidade da doença. Goodwin, na década de 60 , define as cardiomiopatias como sendo doenças primárias do músculo cardíaco. A classificação, baseada em alterações da estrutura e função, foi introduzida em 1964, com as cardiomiopatias apresentando-se clinicamente de três maneiras: tipo congestivo, tipo constritivo e tipo obstrutivo. Com o passar do tempo, o termo congestivo, em que o diagnóstico era feito com a manifestação dos sintomas de insuficiência cardíaca, foi substituído pelo termo dilatada. Em relação ao termo obstrutivo, como a maior apresentação é a hipertrofia ventricular idiopática, passou a ser chamado de hipertrófico. O termo constritivo/obliterativo passou a ser denominado restritivo ${ }^{2}$.

Passados quase 90 anos da primeira descrição, a WHO/ISFC Task Force ${ }^{3}$ define o conceito de cardiomiopatia como sendo uma doença muscular de causa desconhecida. Desordens do miocárdio causadas por hipertensão sistêmica e pulmonar, doenças valvares, coronária e congênitas tinham que ser excluídas. Classifica as cardiomiopatias em três grupos distintos: dilatada, hipertrófica e restritiva. Classificação que passou a ter grande aceitação entre a comunidade médica, sendo poucas categorias de doenças não preenchidas em nenhum grupo.

Instituto do Coração do Hospital das Clínicas - FMUSP

Correspondência: Charles Mady - Incor - Divisão Clínica - Av. Dr. Enéas C. Aguiar, 44 - 05403-000 - São Paulo, SP

Recebido para publicação em 13/6/97

Aceito em 27/8/97
Esta discussão semântica não gerou esclarecimentos maiores na uniformização de conceitos. Quando o termo cardiomiopatia foi introduzido, houve a intenção de se conceituar o acometimento miocárdico de origem não definida, idiopática, que nada mais é do que o resultado de nossa ignorância sobre a etiopatogenia do processo. Pode-se subentender, conseqüentemente, que com o avanço dos conhecimentos, esta entidade tende a diminuir de incidência, até desaparecer. Estes pontos tornam-se ainda mais importantes por abranger um grupo muito grande de pacientes. Para aumentar a discussão, muitos autores usam a terminologia "cardiomiopatia idiopática", o que, pelo exposto, é pleonasmo. Além disso, é interessante observar que as doenças pretensamente idiopáticas do pericárdio e endocárdio não passaram a se chamar cardiopericardiopatias e cardioendocardiopatias, apesar de serem pericardiopatias "idiopáticas" e endocardiopatias "idiopáticas". Então, porquê apenas com a miocardiopatia? Não seria mais lógico ter continuado a utilização da terminologia miocardiopatia idiopática, ou primária, na ausência de diagnóstico etiológico estabelecido, e secundária, quando o agente é conhecido? A ânsia de modificações, muitas vezes, gera mais problemas do que aqueles cujas modificações se propõem resolver.

Para aumentar ainda mais a discussão, o termo "congestiva", proveniente de miocardiopatia congestiva, foi substituído por dilatada, tentando se dar uma caracterização anatômica em uma classificação previamente fisiopatológica. Este comentáriojá seria uma primeira crítica à modificação. Sabemos entretanto, que pacientes em fase inicial de miocardiopatia podem não demonstrar dilatação, manifestada somente, quando são submetidos a algum tipo de estresse $^{4}$, e que, quando interrompida, a geometria ventricular retorna ao normal. Seria a fase inicial de miocardiopatia dilatada, mas ainda sem dilatação em repouso. Fato que interroga a utilização desse termo, colocado para substituir a palavra congestiva, que talvez seja menos inexato, pois dificilmente um indivíduo com dilatação de ventrículos não apresenta congestão, supostamente subclínica, mas fisiopatologicamente presente. Pelo exposto, julgamos que a terminologia miocardiopatia congestiva, já praticamente abandonada, é a menos inexata.

Em relação ao termo obstrutivo, houve uma mudança correta para hipertrófico, pois, nem todas as miocardiopatias hipertróficas são fisiopatologicamente obstru- 
tivas e esta é a doença mais freqüente, nesse conjunto de pacientes. Os termos constritivo e obliterativo também, de forma correta, foram substituídos por restritivo, por determinarem uma síndrome fisiopatológica restritiva.

Em 1995, a WHO/ISFC Task Force ${ }^{1}$ publicou novo artigo sobre definição e classificação das cardiomiopatias, como sendo doenças do miocárdio com disfunção, classificando-as, como: cardiomiopatia dilatada, cardiomiopatia hipertrófica, restritiva e cardiomiopatia arritmogênica do ventrículo direito.

É interessante observar que descrevem "doença do miocárdio com disfunção". E as doenças do miocárdio sem disfunção aparente? Ou em repouso? E onde classificar-seiam a forma indeterminada de doença de Chagas e as formas não dilatadas com alterações eletrocardiográficas?

A WHO/ISFC incluem nesse setor as cardiomiopatias não classificadas, doenças que não se enquadram em nenhum grupo, como a fibroelastose e envolvimento mitocondrial.

Nas cardiomiopatias específicas enquadram-se as doenças musculares cardíacas as quais estão associadas com desordens cardíacas específicas ou sistêmicas, anteriormente, chamadas de doenças musculares específicas do coração. São elas a cardiomiopatia isquêmica, cardiomiopatia valvular, cardiomiopatia hipertensiva, cardiomiopatia inflamatória, cardiomiopatia metabólica, cardiomiopatia periparto, doenças sistêmicas gerais, distrofias musculares, desordens neuromusculares, reações de sensi- bilidade e tóxicas. Em nossa opinião, a simples menção da causa, sucedendo o termo cardiomiopatia ou miocardiopatia, já resolve o problema de forma simples e objetiva. Aliás, quanto mais simples e objetiva for a classificação, mais facilmente os clínicos a utilizarão e a perpetuarão, o que, infelizmente, não vem ocorrendo ultimamente.

Outra dificuldade dessa classificação reside no fato de que em alguns casos ocorre um entremeado de alterações, podendo gerar confusão na classificação, como por exemplo, pacientes com miocardiopatia restritiva, que podem apresentar graus variáveis de hipertrofia e, até mesmo, desaranjo de fibras, achado mais freqüente na cardiomiopatia hipertrófica. Outras dificuldades práticas também encontradas são: pacientes atletas com coração hipertrofiado com arritmias, pacientes idosos com alterações de relaxamento ventricular e sinais clínicos de insuficiência cardíaca com função ventricular normal. Além disso, descrevem "doença do miocárdio com disfunção". Novamente perguntamos: e as doenças do miocárdio sem disfunção aparente? Ou em repouso? Talvez num futuro, não tão distante, com maior conhecimento genético das cardiomiopatias, todas as dúvidas possam ser dissipadas ${ }^{5}$.

Concluindo, toda classificação é passível de falhas, críticas e dificilmente resiste ao tempo, como diz Goodwin: Qualquer classificaçãoé necessariamente incompleta e funciona como uma ponte entre a ignorância completa e a total compreensão".

\section{Referências}

1. WHO/ISFC - Report of the WHO/ISFC Task Force on the definition and classification of cardiomyopathies. Circulation 1996; 93: 841-2.

2. Goodwin J - The frontiers of cardiomyopathy. Br Heart J 1982; 48: 1-18.

3. WHO/ISFC - Report of the WHO/ISFC Task Force on the definition and classification of cardiomyopathies. Br Heart J 1980; 44: 672-3.
4. Mady C, Barretto ACP, Nacruth R, Mesquita ET, Bellotti G, Pileggi F-Maximal functional capacity in patients with cardiomyopathy due to Chagas'disease without congestive heart failure. J Am Coll Cardiol 1993; 103A.

5. Keren A, Pop R - Assignment of patients into the classification of cardiomyopathies. Circulation 1992; 86 1622-33. 